\title{
Counsellors in English and Welsh general practices: their nature and distribution
}

\author{
Bonnie Sibbald, Julia Addington-Hall, Douglas Brenneman, Paul Freeling
}

\begin{abstract}
Objective-To establish the prevalence of counselling services in English and Welsh general practices and factors associated with their distribution; to describe qualifications, working arrangements, and case mix of "counsellors."

Design-Postal questionnaire and telephone interview survey of a sample of about one in 20 general practitioners in England and Wales.

Setting-English and Welsh general practices.

Subjects-1880 general practitioners, of whom $1542(82 \%)$ completed questionnaires.
\end{abstract}

Main outcome measures-Prevalence and distribution of practice counselling services; counsellors' qualifications and funding; types of patients referred.

Results-586 counsellors were distributed among 484 of the 1542 practices. Three types of counsellor predominated: community psychiatric nurses (187); "practice counsellors" (145); and clinical psychologists (95). Practice characteristics which independently predicted the presence of a counsellor were for community psychiatric nurses four or more partners (odds $=1 \cdot 72,95 \%$ confidence interval $1 \cdot 18$ to $2 \cdot 26$ ) ; for practice counsellors stress clinic (odds= $2 \cdot 22 ; 1.83$ to 2.61 ), training practice (odds $=1 \cdot 70$; $1 \cdot 24$ to $2 \cdot 16)$, and health region $\left(\chi^{2}=55.94 ; \mathrm{df}=14\right.$; $p<0.001$ ); and for clinical psychologists list size of $\geqslant 10500$ (odds $=1.79 ; 1.09$ to 2.49 ), training practice (odds $=1 \cdot 78 ; 1.31$ to $2 \cdot 25)$, health region $\left(\chi^{2}=48 \cdot 31\right.$; df $=14 ; p<0.001) .197$ counsellors had training in counselling. The qualifications of 85 were unknown to the general practitioner. The principal source of funding was the district health authority for community psychiatric nurses (150) and clinical psychologists (58) and the family health services authority for practice counsellors (76). All counsellors were referred a wide range of problems.

Conclusions-Counselling services are widespread in general practice, but a high proportion of counsellors lack qualifications, and many may be referred problems outside their knowledge.

\section{Introduction}

There is considerable interest in developing appropriate health care for general practice patients with psychiatric morbidity. Concern about the efficacy, safety, and cost of psychotropic drugs ${ }^{12}$ has increased interest in non-drug treatments, such as behavioural therapy and counselling. General practitioners, however, may lack the time or skills to counsel patients, ${ }^{3-6}$ and one response has been schemes whereby mental health professionals work alongside general practitioners. $^{7-12}$ Another widespread response has been the addition of practice counsellors to the primary health care team. ${ }^{13}$

Little is known about the nature, distribution, or effectiveness of these counselling services. Corney points to the difficulty of evaluating a service whose practitioners vary greatly in their training, therapeutic approach, and case mix. ${ }^{14}$ Some counsellors have psychotherapeutic training; some are trained by Relate (formerly the Marriage Guidance Council); others have little or no formal training. ${ }^{6}$ Their work ranges from counselling mildly disturbed patients to treating patients with severe psychiatric morbidity and helping change behaviours such as smoking and alcohol abuse. ${ }^{6}$

Counselling services appear unevenly distributed among practices, raising concern about the equity of provision. In the largest reported survey, Thomas and Corney found counsellors working in $17 \%$ of 261 general practices, mainly those with large partnerships located in health centres. ${ }^{13}$ The prevalence of counsellors differed greatly between health authority areas, possibly due to differences among family health service authorities in their policies about reimbursing counsellors' salaries.

The benefits and costs to patients, practices, and the NHS of providing counselling services within general practice have yet to be established. Several studies suggest that counselling can improve patients' feeling of well being and may reduce prescribing of psychotropic drugs, consultation rates, or referral to psychiatric services. ${ }^{14}$ Others, however, suggest that counsellors may not be cost effective. ${ }^{15}$ Much of this work, however, was based on small samples, lacked objective measures of outcome, or had limited follow up.

As a first step in improving understanding of the counselling services provided within general practices we conducted a detailed survey of the nature and distribution of practice counsellors within English and Welsh general practices.

\section{Methods}

\section{SAMPLING}

The study group consisted of a sample of about one in 20 general practitioners in England and Wales, stratified by family health services authority area and partnership size. General practitioners were identified from records held by the Department of Health, which was asked to select at random seven singlehanded general practitioners, seven from partnerships of two or three, and 20 from partnerships of four or more for each family health services authority. From this sample we randomly selected 57 of the 98 family health services authorities for inclusion in this investigation.

\section{QUESTIONNAIRE}

The data were collected using a structured questionnaire administered either by post or by telephone interview. The questionnaire was confidential, but not anonymous, and covered a range of practice charac-

Dr Sibbald. 
teristics including: partnership size; list size; average number of patients per general practitioner; personal list system or not; training practice or not; budget holding practice or not; urban, suburban, or rural location; health region; percentage of patients aged 75 years or over; percentage of patients of non-European origin; social class mix of patients; number of partners with a special interest in psychiatry; and number and type of health promotion clinics approved by the family health services authority. The questionnaire also covered: information about psychiatric, psychological, and counselling services currently available on site; and, for those with counsellors, the number of counsellors, their qualifications, types of patients referred to them, and funding.

There is no consensus over the definition of counselling. For this study we asked general practitioners whether there was a person working on site or within the practice who fulfilled the following definition: "Someone who offers (formal) sessions to patients in which patients are helped to define their problems and enabled to reach their own solutions. General practitioners and others provide counselling in the ordinary course of their work, but we need to know about the provision of counselling as a distinct or separate activity within the practice."

\section{METHODS OF ADMINISTRATION}

Doctors were mailed the questionnaire together with a prepaid reply envelope. Non-responders were sent up to two further reminders. When possible, those who had still not responded were administered the identical questionnaire by telephone.

To investigate the possible differences between telephone and postal administration of the questionnaire, we drew a random sample of 206 general practitioners and approached them first by telephone. This permitted us to examine the differences among those first approached by telephone, those first approached by postal questionnaire, and those approached by telephone because they had failed to respond to the postal questionnaire. The findings will be reported in detail elsewhere but the relevant results are summarised here.

ANALYSIS

Data were analysed using the Statistical Package for the Social Sciences (SPSS/PC+). Analysis focused on identifying the differences between practices with and without counsellors. For simplicity of presentation, interval type variables were dichotomised using a cut off point which most nearly divided the population in half. The significance of the association between the presence of a counsellor and each practice characteristic was then assessed using the $\chi^{2}$ statistic. Given the large number of comparisons we report only those findings whose level of significance reached $p<0.01$, thereby excluding findings of marginal significance which may have arisen by chance alone. The findings are presented as the odds of having a counsellor for a given practice characteristic - that is, odds ratio and its $95 \%$ confidence interval.

To examine the effect of each practice characteristic, while controlling for others, we used logistic regression analysis. A model was fitted for each type of counsellor and included all factors found to be significantly associated with the presence of that type of counsellor. The findings are reported as the odds of having an on site counsellor for a given practice characteristic after controlling for the other practice characteristics-that is, adjusted odds ratio and $95 \%$ confidence interval. The significance of the effect of health region was estimated by taking the difference in the logistic regression model $\chi^{2}$ values with and without health region fitted.
Results

STUDY GROUP

Of the 1732 general practitioners contacted initially by post, 49 had died, retired, or moved. Of the 1683 presumed still to be in post $881(53 \%)$ completed the postal questionnaire and a further $494(30 \%)$ completed the telephone interview. Of the 206 general practitioners contacted initially by telephone, nine had died, retired, or moved. Of the 197 presumed still to be in post $167(85 \%)$ completed the interview. In total, usable questionnaires were obtained from $1542(82 \%)$ of the 1880 general practitioners who were eligible to take part.

Doctors contacted by telephone were more likely than those responding by post to report having a person on site who provided counselling according to the study definition. No such difference was found for counsellors who had no other job in the practice and the analysis was therefore restricted to this group.

The 1542 responding general practitioners reported the presence on site or within their practices of 586 people who fulfilled the study definition of counsellor and had no other job in the practice. Three types of counsellor predominated: community psychiatric nurses; "practice counsellors"; and clinical psychologists. These three groups together comprised $427 / 586$ $(73 \%)$ of all counsellors and $410 / 484(85 \%)$ of all practices with a counsellor. Subsequent analyses therefore focused on these three types of counsellor.

\section{PREVALENCE OF COUNSELLORS}

A total of $484(31 \%)$ of 1542 practices had a counsellor by our definition-181 a community psychiatric nurse; 134 a practice counsellor; and 95 a clinical psychologist (table I). Counsellors in the

TABLE I-Distribution of counsellors on site within English and Welsh general practices by region. Results are percentages (and number) of practices

\begin{tabular}{|c|c|c|c|c|}
\hline \multirow[b]{2}{*}{ Health region } & \multirow[b]{2}{*}{$\begin{array}{c}\text { No } \\
\text { of } \\
\text { practices }\end{array}$} & \multicolumn{3}{|c|}{ Type of counsellor } \\
\hline & & $\begin{array}{l}\text { Community } \\
\text { psychiatric } \\
\text { nurse }\end{array}$ & $\begin{array}{l}\text { Practice } \\
\text { counsellor }\end{array}$ & $\begin{array}{c}\text { Clinical } \\
\text { psychologist }\end{array}$ \\
\hline East Anglia & 53 & $9(5)$ & $11(6)$ & $2(1)$ \\
\hline Mersey & 79 & $8(6)$ & $23(18)$ & $14(11)$ \\
\hline North East Thames & 83 & $15(12)$ & $8(7)$ & $8(7)$ \\
\hline North West Thames & 112 & $21(24)$ & $8(9)$ & $2(2)$ \\
\hline North Western & 134 & $8(10)$ & $13(17)$ & $14(19)$ \\
\hline Northern & 151 & $17(26)$ & $8(12)$ & $5(7)$ \\
\hline Oxford & 78 & $8(6)$ & $17(13)$ & $0(0)$ \\
\hline South East Thames & 90 & $13(12)$ & $9(8)$ & $6(5)$ \\
\hline South West Thames & 81 & $9(7)$ & $10(8)$ & $3(2)$ \\
\hline South Western & 107 & $10(11)$ & $16(17)$ & $8(9)$ \\
\hline Trent & 133 & $11(15)$ & $5(7)$ & $7(9)$ \\
\hline Wales & 116 & $12(14)$ & $2(2)$ & $4(5)$ \\
\hline Wessex & 85 & $12(10)$ & $1(1)$ & $1(1)$ \\
\hline West Midland & 126 & $12(15)$ & $5(6)$ & $8(10)$ \\
\hline Yorkshire & 114 & $7(8)$. & $3(3)$ & $6(7)$ \\
\hline Total & 1542 & $12(181)^{\star}$ & $9(134)^{\star \star}$ & $6(95)^{\star \star}$ \\
\hline
\end{tabular}

Significance of difference among regions $\chi^{2:}{ }^{\star} \mathrm{p}=0.046 ;{ }^{\star \star} \mathrm{p}<0.001$.

remaining 74 practices comprised a variety of staff, including general practitioners, practice nurses, and health visitors. Since partnership size influenced the likelihood of having an on site counsellor (see below), the observed prevalences were adjusted to reflect the actual distribution of partnership sizes in England. ${ }^{10}$ The observed and adjusted prevalences did not differ because, by chance, the dearth of counsellors in singlehanded partnerships balanced the excess in large partnerships within our sample.

\section{FACTORS ASSOCIATED WITH THE PRESENCE OF} COUNSELLORS

The odds of having a counsellor for each practice characteristic found to meet our criterion of statistical significance are shown in table II. Those practice characteristics associated with an increased likelihood 
of having any sort of counsellor included: partnerships of four or more doctors; list sizes of 10500 or more; and being a training practice. Health region was associated with considerable variation in the prevalences of on site practice counsellors and clinical psychologists, but not community psychiatric nurses (table I).

Logistic regression analysis was then used to examine the effect of each practice characteristic while controlling for the others. The adjusted odds of having a counsellor are summarised in table II for those practice characteristics which remained statistically significant. Large practices and training practices were more likely than others to have an on site counsellor. Health region independently predicted the presence of practice counsellors $\left(\chi^{2}=55.94 ; \mathrm{df}=14 ; \mathrm{p}<0.001\right)$ and clinical psychologists $\left(\chi^{2}=48.31 ; \mathrm{df}=14 ; \mathrm{p}<0.001\right)$ but not community psychiatric nurses $\left(\chi^{2}=22 \cdot 25 ; \mathrm{df}=14 ; \mathrm{p}>0.05\right)$.

Regional variations in the prevalence of counsellors were probably related to sources of funding. We therefore examined patterns of funding within regions grouped in tertiles according to the prevalence of on site counsellors (table III). Those regions with a low prevalence of either practice counsellors or clinical psychologists tended to have proportionately fewer such counsellors covered by reimbursements from family health services authorities. These differences, however, were small and did not reach statistical significance.

\section{BARRIERS TO PROVIDING A COUNSELLOR}

A total of 875 doctors said that their practice provided a counselling service, although this did not always meet our criteria. The 667 doctors who did not have a counsellor were asked if they would like to provide one: 413 said they would, 85 were opposed, 144 were uncertain, and 25 failed to respond. Those who said they would like a counsellor were asked to describe the barriers to providing one. Among the 390 who responded, the barriers included: financial constraints (251); lack of space (136); lack of time (81); staffing difficulties (72); low demand (29); doubtful

TABLE II-Odds of having an on site counsellor given different practice characteristics

\begin{tabular}{|c|c|c|}
\hline \multirow[b]{2}{*}{ Practice characteristics } & \multicolumn{2}{|c|}{ Odds ratio ( $95 \%$ confidence limit) } \\
\hline & Unadjusted & Adjusted ${ }^{\star}$ \\
\hline \multicolumn{3}{|c|}{ Community psychiatric nurse } \\
\hline$\geqslant 4$ partners & $1.80(1.31$ to 2.60$)$ & $1.72(1.18$ to 2.26$)$ \\
\hline$\geqslant 10500$ patients & $1.61(1.17$ to 2.22$)$ & NS \\
\hline Training practice & $1.49(1.08$ to 2.05$)$ & NS \\
\hline \multicolumn{3}{|l|}{ Practice counsellor } \\
\hline Stress clinic & $2.60(1.82$ to 3.72$)$ & $2.22(1.83$ to 2.61$)$ \\
\hline$\geqslant 4$ partners & $1.88(1.27$ to 2.79$)$ & NS \\
\hline$\geqslant 10500$ patients & $1.68(1.16$ to 2.43$)$ & NS \\
\hline Training practice & $2.06(1.44$ to 2.95$)$ & $1.70(1.24$ to 2.16$)$ \\
\hline \multicolumn{3}{|l|}{ Clinical psychologist } \\
\hline Stress clinic & $1.85(1.21$ to 2.82$)$ & NS \\
\hline Total of $3+$ clinics & $1.58(1.04$ to 2.41$)$ & NS \\
\hline$\geqslant 4$ partners & 2.91 (1.74 to 4.87$)$ & NS \\
\hline$\geqslant 10500$ patients & $2.72(1.71$ to 4.32$)$ & $1.79(1.09$ to 2.49$)$ \\
\hline Training practice & $2.23(1.46$ to 3.40$)$ & $1.78(1.31$ to 2.25$)$ \\
\hline
\end{tabular}

ॠOdds after controlling for other practice characteristics (including health region).

NS $=$ not significant

TABLE II-Sources of funding for counsellors within health regions grouped according to the prevalence of on site counsellors. Results are percentages (and numbers) of counsellors

\begin{tabular}{lccccc}
\hline & $\begin{array}{c}\text { Family health } \\
\text { services authority }\end{array}$ & Practice & $\begin{array}{c}\text { District health } \\
\text { authority }\end{array}$ & Other & Total \\
\hline Practice counsellors in: & & & & & \\
$\quad$ Highest prevalence regions & $62(46)$ & $11(8)$ & $1(1)$ & $26(19)$ & $100(74)$ \\
Middle prevalence regions & $51(22)$ & $14(6)$ & $7(3)$ & $28(12)$ & $100(43)$ \\
$\quad$ Lowest prevalence regions & $38(8)$ & $14(3)$ & $5(1)$ & $43(9)$ & $100(21)$ \\
Clinical psychologist counsellors in: & & & & & \\
Highest prevalence regions & $29(16)$ & $5(3)$ & $55(31)$ & $11(6)$ & $100(56)$ \\
Middle prevalence regions & $27(9)$ & $0(0)$ & $61(20)$ & $12(4)$ & $100(33)$ \\
Lowest prevalence regions & $17(1)$ & $0(0)$ & $67(4)$ & $17(1)$ & $100(6)$ \\
\hline
\end{tabular}

^Employed by practice with family health services authority reimbursement.

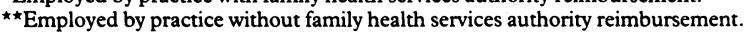

TABLE IV-Description of counsellors: qualifications and working arrangements. Results are percentages (and numbers) of counsellors

\begin{tabular}{lccc}
\hline & $\begin{array}{c}\text { Community } \\
\text { psychiatric } \\
\text { nurse } \\
(187)\end{array}$ & $\begin{array}{c}\text { Practice } \\
\text { counsellor } \\
(145)\end{array}$ & $\begin{array}{c}\text { Clinical } \\
\text { psychologist } \\
(95)\end{array}$ \\
\hline Qualifications & & & \\
Nil known & $14(27)$ & $28(19)$ & $30(32)$ \\
British Association of Counselling & $8(15)$ & $48(69)$ & $23(22)$ \\
Registered general nurse & $33(61)$ & $8(12)$ & $1(1)$ \\
Community psychiatric nurse & $79(147)$ & $4(6)$ & $2(2)$ \\
Social work & $2(4)$ & $11(16)$ & $1(1)$ \\
Health visitor & $0(0)$ & $1(2)$ & $1(1)$ \\
Relate & $0(0)$ & $12(17)$ & $4(4)$ \\
Counselling course & $11(21)$ & $32(46)$ & $35(33)$ \\
Psychotherapy course & $13(24)$ & $21(31)$ & $28(36)$ \\
Psychology degree & $0(0)$ & $3(4)$ & $17(16)$ \\
Other & $4(7)$ & $10(15)$ & $8(8)$ \\
Work arrangements (h/wk): & & & \\
Mean & $7 \cdot 3$ & $7 \cdot 4$ & $4 \cdot 0$ \\
Lower quartile & 3 & 3 & 3 \\
Upper quartile & 9 & 10 & 5 \\
Funding source: & & & \\
Family health services authority & $8(14)$ & $52(76)$ & $27(26)$ \\
Practice $\star \star$ & $3(6)$ & $12(17)$ & $3(3)$ \\
District health authority & $80(150)$ & $3(5)$ & $58(55)$ \\
Other & $4(8)$ & $28(40)$ & $12(11)$ \\
\hline
\end{tabular}

^Employed by practice with family health services authority reimbursement. ${ }^{\star \star}$ Employed by practice without family health services authority ment. ${ }^{\star \star}$ Employed

Qualifications held by counsellors do not total $100 \%$ since individuals may hold more than one qualification.

TABLE V-Problems referred by general practitioners to on site counsellors. Results are percentages (numbers) of counsellors

\begin{tabular}{lccc}
\hline & $\begin{array}{c}\text { Community } \\
\text { psychiatric } \\
\text { nurse } \\
(187)\end{array}$ & $\begin{array}{c}\text { Practice } \\
\text { counsellor } \\
(145)\end{array}$ & $\begin{array}{c}\text { Clinical } \\
\text { psychologist } \\
(95)\end{array}$ \\
\hline Relationship problems: & & & \\
$\quad$ Marital, family relationship & $78(149)$ & $86(125)$ & $75(71)$ \\
Bereavement & $75(140)$ & $85(123)$ & $68(65)^{\star \star}$ \\
Psychosexual problems & $34(63)$ & $47(68)$ & $59(56)^{\star \star \star}$ \\
Adjustment to disability & $47(87)$ & $59(85)$ & $58(55)$ \\
Stress related illness & $82(153)$ & $78(113)$ & $81(77)$ \\
Substance misuse & & & \\
Alcohol dependency & $42(78)$ & $31(45)$ & $31(29)$ \\
Therapeutic drug dependency & $37(68)$ & $24(35)$ & $30(28)$ \\
Smoking cessation & $9(17)$ & $12(17)$ & $12(11)$ \\
Eating disorder, obesity & $29(55)$ & $32(46)$ & $50(47)^{\star}$ \\
Psychiatric problems & & & \\
Anxiety, depression & $90(169)$ & $77(111)$ & $83(79)^{\star \star}$ \\
Phobias & $72(134)$ & $42(61)$ & $87(83)^{\star \star \star}$ \\
Obsessions, compulsions & $65(122)$ & $31(45)$ & $77(73)^{\star \star \star}$ \\
Personality disorder & $54(100)$ & $36(52)$ & $48(46)^{\star \star}$ \\
Psychotic illness & $48(89)$ & $7(10)$ & $13(12)^{\star \star \star}$ \\
\hline
\end{tabular}

Significance of difference among types of counsellor $\left(\chi^{2}\right):{ }^{\star} p<0.05$ $\star \star \mathrm{p}<0.01 ; \star \star \star \mathrm{p}<0.001$.

value of counselling (15); and miscellaneous other reasons (52).

\section{DESCRIPTION OF COUNSELLORS}

General practitioners were asked to state which qualifications, from a list of possibilities, were held by their counsellor (table IV). Nearly half had had specialist training in counselling-106 were accredited by the British Association of Counselling, and a further 91 were trained by Relate or had completed a counselling or psychotherapy course. Overall general practitioners did not know what counselling qualifications, if any, were held by 85 of their counsellors.

Counsellors were reported to work an average of $6 \cdot 6$ hours a week (range 1-40). Practice counsellors worked the longest number of hours, followed by community psychiatric nurses and clinical psychologists.

The principal sources of funding for counsellors varied by type of counsellor (table IV). Most community psychiatric nurses were funded by district health authorities and none were funded by contributions from patients. In contrast, half the practice counsellors were employed by the practice with reimbursement from the family health services authority, and over a quarter were funded from miscellaneous sources, which included Relate (marriage guidance service) and charitable trusts such as the Mental Health 
Foundation. Seventeen were funded in part from contributions made by patients. More than half the clinical psychologists were funded by the district health authority and over a quarter by the practice with reimbursement. Only one was funded in part by contributions from patients.

General practitioners were asked which problems from a list of possibilities the practice referred to its counsellor (table V). Each type of counsellor was referred the full range of patient problems, although the balance of problems differed significantly among them. Community psychiatric nurses were more likely to be referred patients with anxiety or depression, personality disorder, or psychotic illness; practice counsellors bereaved patients; and clinical psychologists patients with psychosexual problems, eating disorders, phobias, or obsessive-compulsive disorders.

\section{Discussion}

LIMITATIONS OF STUDY

The focus of this study was on counselling provided as a distinct or separate service within practices. The prevalence of such services was based on general practitioners' reports, raising the possibility of bias in their interpretation of our definition of counselling. Indeed, because we thought that general practitioners were not always careful to distinguish between counselling skills used within routine clinical work and counselling provided as a distinct service we excluded counsellors who were reported to have other jobs within the practice. In so doing, we will have excluded some clinical professionals who genuinely provide counselling. The net effect of these limitations is to provide a conservative estimate of the true prevalence of counselling services. The advantage of this approach was our ability to focus on comparatively well defined types of counsellors, who, by virtue of having no other job within practice, may have the greatest impact on service development and its costs.

The qualifications, working arrangements, and case mix of the counsellors were also based on general practitioners' reports and were therefore vulnerable to inaccuracy. The data should, however, give an accurate picture of general practitioners' views of counsellors and the services they provide.

\section{PREVALENCE AND DISTRIBUTION OF COUNSELLORS}

The reported prevalence of counsellors on site within English and Welsh general practices was high, confirming previous suggestions that such services have grown rapidly within British general practice. ${ }^{13}$ Our findings suggest that $31 \%$ of all general practices now have counsellors with no other job in the practice. More than four fifths of the general practitioners who did not have a counselling service said they wished to provide one, indicating the potential for further growth. The principal barriers to providing a counsellor were said to be financial constraints and lack of space.

Community psychiatric nurses, "practice counsellors," and clinical psychologists constituted most counsellors. Although these three types of counsellor were distributed differently among practices (table II), large practices and training practices were more likely than others to have counsellors. This is not surprising in that large practices will be better able to provide the accommodation, generate the workload, and raise the funds needed to support a counsellor. Training practices are often in the forefront of innovation within general practice and so might also be expected to have a high prevalence of counsellors.

The presence of a practice counsellor on site was additionally, and independently, associated with the provision of a stress clinic. The new general practitioner contract provides financial incentives for the establish- ment of stress clinics and permits general practitioners to be reimbursed $70 \%$ of the salary costs needed to staff such clinics. General practitioners seem to have made use of these contract changes to establish stress clinics staffed by counsellors who may then undertake a wider range of work within the practice.

The prevalence of counsellors varied significantly among health regions. This variation was not fully explained by differences in the proportions of large practices, training practices, or practices with a stress clinic. There was some evidence, however, that differences in the availability of funding for counsellors might be a contributing factor. Over half of practice counsellors and a quarter of clinical psychologists were funded in part by the family health services authority, and in regions with the lowest prevalence of such counsellors proportionately fewer were funded by family health services authorities. Anecdotal reports suggest that authorities differ in their policies for reimbursing the costs of counsellors. ${ }^{13}$ General practitioners themselves volunteered that financial constraints were the biggest barrier to providing a counselling service. Taken together, these findings suggest that family health services authority policies underlie regional variations in the distribution of counsellors. However, a survey of such policies is needed to confirm or refute this hypothesis.

\section{COUNSELLORS' QUALIFICATIONS}

General practitioners were unaware of what counselling qualifications were held by a fifth of the people who provided this service within their practices. Although it is regrettable that so many were prepared to delegate patient care to people whose qualifications were unknown to them, there is little to guide general practitioners in selecting appropriate staff. There is no accepted accreditation scheme for counsellors, and their training, practice, and supervision vary greatly. ${ }^{6}$ In selecting a counsellor, general practitioners may rely more on their personal knowledge of the therapist than on formal qualifications.

In this study 145 of the 342 counsellors whose qualifications were known to the general practitioner had had no training in counselling. A recent survey of cancer counsellors within Britain showed even higher proportions without relevant qualifications. ${ }^{17}$ This is unimportant if training has no effect on the quality of care or outcomes for patients. A recent review by Corney of investigations into counselling within general practice suggests that, although counselling has significant benefit for many patients, evidence that training improves outcome is equivocal. ${ }^{14}$ In addition, Corney points out that there is often a greater variance in outcomes for treated clients than for untreated controls, suggesting that some individuals may be harmed by counselling. Clearly more needs to be learnt about the efficacy and safety of different counselling interventions, and the role of training, before any nationally approved training or accreditation scheme can be recommended.

\section{WORK UNDERTAKEN BY COUNSELLORS}

General practitioners' referral patterns were found to vary with the type of counsellor on site, reflecting general practitioners' perceptions of the likely skills of their counsellors. Affective and psychotic disorders tended to be directed to community psychiatric nurses, which suggests that general practitioners see these nurses as skilled in the management of psychiatric illness. Clinical psychologists tended to be referred problems such as psychosexual difficulties, eatin disorders, phobias, and obsessive-compulsive disorders, which are believed amenable to the behavioural therapies practised by these professionals. Bereaved patients were most often directed to practice counsel- 
lors, which suggests that general practitioners view bereavement as a problem which responds to the nondirective forms of counselling associated with these professionals.

As in previous studies, ${ }^{614}$ our findings showed also that each type of counsellor was referred a wide variety of problems ranging from family and relationship difficulties to substance misuse and psychiatric illness. While many counsellors may be skilled in a range of therapeutic approaches, any one type of counsellor is unlikely to be qualified to deal with such a broad range of illness. Many must have been called on to treat patient problems outside their knowledge. General practitioners will need to become more discriminating in their referral policies if they are to maximise the benefits of their counselling services. They must be helped in this task by better research into which types of patient problems are best treated by which types of psychological intervention. We plan further studies into the work of selected counsellors and their impact on referral rates and psychotropic drug use.

We thank the Department of Health for drawing the sample of general practitioners on our behalf; Peter Bower and Fel Oakes for their help with data collection; and the many general practitioners who participated in the study. The work was funded by a grant from the Mental Health Foundation.
1 Eastman C, McPherson I. As others see us: general practitioners' perceptions of psychological problems and the relevance of clinical psychology. Br $\mathcal{J}$ Clin Psychol 1982;21:85-92.

2 Gath D, Catalan J. The treatment of emotional disorders in general practice: psychological methods versus medication. F Psychosom Res 1986;30:381-6.

3 Martin E. Counsellors in general practice. BMJ 1988;297:637-8.

4 Deans HG, Skinner P. Doctors' views on anxiety management in general practice. $3 R$ Soc Med 1992;85:83-6.

5 Rowland N, Irving J, Maynard A. Can general practitioners counsel? f $R$ Coll Gen Pract 1989;39:118-20.

6 MacLeod J. The work of counsellors in general practice. London: Royal College of General Practitioners, 1988 (Occasional paper 37).

7 Strathdee G. Primary care-psychiatry interaction: a British perspective. Gen Hosp Psychiatry 1987;9:102-10.

8 Mitchell ARK. Participating in primary care: differing styles of psychiatric liaison. Psych Bull 1989;13:135-7.

9 Tyrer P. Pyychiatric clinics in general practice: an extension of community care. Br f Psychiatry 1984;145:9-14.

10 Robson $\mathrm{MH}$, France $R$, Bland $M$. Clinical psychologists in primary care controlled clinical and economic evaluation. $B M \Im 1984 ; 288: 1805-8$.

11 Long CG, Bourne V. Linking professional and self-help resources for anxiety management: a community project. $f R$ Coll Gen Pract 1987;37:199-201

12 Trepka C, Griffiths T. Evaluation of psychological treatment in primary care. IR Coll Gen Pract 1987;37:215-7.

13 Thomas RVR, Corney RH. A survey of links between mental health professionals and general practice in six district health authorities. $\mathrm{Br} \mathcal{F} \mathrm{Gen}$ Pract 1992;42:358-61.

14 Comey RH. Counselling in general practice-does it work? Discussion paper. fR Soc Med 1990;83:253-7.

15 Scott AI, Freeman CPL. Edinburgh primary care depression study: treatment Scott AI, Freeman CPL. Edinburgh primary care depression study: treatment
outcome, patient satisfaction, and cost after 16 weeks. $B M \mathcal{F}$ 1992;304:

16 Department of Health. Health and personal social services statistics for England 1988. London: HMSO, 1988

17 Fallowfield L, Roberts R. Cancer counselling in the United Kingdom. Psychol Health 1992;6:107-17

(Accepted 10 November 1992)

\title{
The Future of FHSAs
}

\section{From FPC to FHSA to ... health commission?}

\author{
June Huntington
}

This is the first in a series of articles on the future of family health services authorities
By 1986 I had worked with general medical practitioners for 16 years, in both the United Kingdom and Australia, but knew nothing of family practitioner committees. While working with a London district health authority in 1986 I met my first family practitioner committee administrator who, when asked whether patients ever came to the office, replied that he was not running a public complaints service.

A week later I attended a meeting of the neighbouring family practitioner committee at which one of the agenda items was the Royal College of General Practitioners' policy document on quality in general practice. ${ }^{\prime}$ A general practitioner member of the committee, who also sat on the district management team of the district health authority, saw fit to remind the chairman, himself a retired pharmacist, that the quality of the general medical services was not within the purview of the family practitioner committee.

Later in 1986 I began to direct a study of the management development needs of family practitioner committees for the NHS training authority, and found that certain of the committees' features uncannily reflected those of general practices. Both were relatively isolated organisations, with few means of exchanging

\section{King's Fund College, London W2 4HS \\ June Huntington, fellow in primary health care} management

\section{Summary}

- The transformation from family practitioner committee to FHSA signalled a shift towards serving the public and servicing rather than serving independent contractors

- FHSAs were charged with improving the range, quality, cost effectiveness, and consumer responsiveness of the family practitioner services component of primary care

- FHSAs were given increased discretion over funding of premises and staff developments in the general medical services, but few sanctions. Impediments to their attempts to procure local improvements, such as the continued powers of the medical practices committee and their own lack of discretion over allocation of Jarman payments, remain

- Nevertheless, most FHSAs have far deeper and more comprehensive knowledge about practice activity than previously, and are increasingly "trading" allocation of resource and development to practices in return for greater practice accountability
- Their closer relationships with GPs have illustrated the difficulties of achieving improved primary health care without greater integration of general medical services with community health services, leading some FHSAs to engage in joint commissioning of primary care with district health authorities

- Fundholding has developed differentially across the country and in some places will soon cover the whole population. Because of the regional health authorities' lead role in establishing fundholding, some FHSAs have remained marginal to this development

- The complexity of services fundholding practices will purchase by April 1993 makes it imperative that they be held accountable, as locally as possible, for their performance as both purchaser and provider. This task will require commissioning authorities that contain members and managers experienced and competent in commissioning both primary and secondary care 